\title{
FIGURAS DE LA
}

DISTANCIA EN LA

TRADUCTOLOGÍA DE

WALTER BENJAMIN

Gabriel Astey*

RESUMEN: Utilizando como principio explicativo la noción de distancia fenomenológica, en el ensayo se exponen las formas de relación entre lengua fuente y lengua meta, y entre texto fuente y texto meta, en la teoría de la traducción de Walter Benjamin.

sose

IMAGES OF DISTANCE IN WALTER BENJAMIN'S TRANSLATOLOGY

ABSTRACT: Using the notion of phenomenological distance as an explanatory principle, we will explore in this article the relationship between source language and target language and between source text and target text in Walter Benjamin's translation theory.

PALABRAS ClAVE: Distancia fenomenológica, traducción ecográfica, traducibilidad, criticabilidad. KEY WORDS: Phenomenological distance, sonic translation, translatability, criticality.

RECEPCIÓN: 4 de agosto de 2016.

APROBACIÓN: 19 de octubre de 2016.

* Departamento Académico de Lenguas, ITAM. 
CITAM Derechos Reservados.

La reproducción total o parcial de este artículo se podrá hacer si el ITAM otorga la autorización previamente por escrito. 


\section{FIGURAS DE LA DISTANCIA EN LA TRADUCTOLOGÍA DE WALTER BENJAMIN}

1. La médula de las reflexiones benjaminianas sobre la traducción literaria se presenta en el breve ensayo que el autor antepuso en 1923 a sus versiones al alemán de los Tableaux parisiens de Baudelaire: Die Aufgabe des Übersetzers ("La tarea del traductor"). ${ }^{1} \mathrm{El}$ texto es célebre tanto por el hermetismo y la densidad conceptual de la prosa del autor, como por la intransigencia con que Benjamin le niega cualquier aspiración comunicativa ${ }^{2}$ a la labor de traducir: tras el aserto de que "ningún poema está destinado al lector", 3

${ }^{1}$ Walter Benjamin, Gesammelte Schriften IV.1 (Herausgegeben von Tillman Rexroth), 1972, Fráncfort del Meno, Suhrkamp, pp. 9-21. Cito siempre esta edición y en todos los casos soy responsable de la traducción de los pasajes, pero he tenido a la vista la versión al español de H. A. Murena ("La tarea del traductor", en Walter Benjamin, Ensayos escogidos, 1999, México, Ediciones Coyoacán, pp. 77-88), así como la hecha al inglés por Harry Zohn ("The task of the translator", en Rainer Schulte y John Biguenet (eds.), Theories of translation: An anthology of essays from Dryden to Derrida, 1992, Chicago, The University of Chicago Press, pp. 71-82). A propósito de las circunstancias editoriales del texto, Benjamin lo "pensaba publicar en el primer número de la revista Angelus Novus. Como esta no llegará a publicarse, este texto lo utilizará como prólogo a sus traducciones [de Baudelaire] cuando fueron editadas por Richard Weisbach, en 1923" (Bruno Tackels, Walter Benjamin. Una vida en los textos, 2012, Valencia, Universitat de València, p. 113).

${ }^{2}$ La palabra comunicación (Mitteilung) tiene en el primer Benjamin dos sentidos, uno idealista y otro semiótico: se trata entonces o de la participación intrínseca de contenidos espirituales (Mitteilung geistiger Inhalte) en el lenguaje, o bien, de la emisión y recepción extrínsecas (äusserlich) de signos convencionales. En el último sentido, en el que se la usa en este momento, la palabra comunicación tiene una connotación despectiva.

${ }^{3}$ Die Aufgabe des Übersetzers, p. 9. 
se lee: “¿Qué ‘dice’ un poema? ¿Qué ‘comunica’? Muy poco, a quienes lo entienden. Por esencia no es comunicativo, ni declarativo. Mas cualquier traducción que pretenda desempeñar una función comunicativa, no puede comunicar sino información, es decir, algo inesencial. He aquí el signo distintivo de las malas traducciones". ${ }^{4}$

Estas afirmaciones resultan aberrantes si se las mira a través de la lente de una traductología de corte positivista que juzgue exitoso el proceso de trasvase textual cuando este se atenga a la "regla de oro" según la cual hay que decir en la lengua meta todo lo que el original dice en la lengua fuente, sin añadir nada que el original no diga, y además decirlo de la mejor manera posible en la lengua meta (esto es, según las pautas léxicas, sintácticas y pragmático-discursivas de esta última). Así las cosas, no causa sorpresa que, a la distancia de las décadas, algunos estudiosos de la traducción vean en el ensayo benjaminiano la más exacerbada exposición del literalismo traductológico tradicional. ${ }^{5} \mathrm{Si}$ bien es cierto que Benjamin indudablemente da pie a esta valoración - entre otras cosas por el hecho de concluir su texto afirmando que "la versión interlineal de las Sagradas Escrituras es el prototipo o ideal de cualquier traducción"- ${ }^{6}$ sería injusto con "La tarea del traductor" descartar en bloque la riqueza de sus tesis con el argumento de que el traductor moderno no puede derivar de ahí más que dos de las herramientas del repertorio de procedimientos de recodificación textual de los que un profesional dispone actualmente: el calco y, en mucho menor medida, la transposición.

Pese a la supuesta rigidez literalista del modelo teórico benjaminiano de la traducción, mi pretensión en este ensayo es mostrar de la forma más clara posible ciertos aspectos hermenéuticos del modelo que dependen del rendimiento heurístico de la noción de distancia fenomenológica, aspectos tanto más difíciles de discernir cuanto que

${ }^{4}$ Loc. cit.

${ }^{5}$ Véase, por ejemplo, Hans Störig, Das Problem des Übersetzens, 1973, Darmstadt, Wissenschaftliche Buchgesellschaft, p. 169; Mary Snell-Hornby, Estudios de traducción. Hacia una perspectiva integradora, 1999, Salamanca, Ediciones Almar, trad. de Ana Sofía Ramírez, p. 27.

${ }^{6}$ Die Aufgabe des Übersetzers, p. 21. 
Benjamin no fue propiamente un fenomenólogo, y además en su propuesta traductológica parece dejar un estrechísimo margen de maniobra a las operaciones interpretativas por parte del traductor.

2. Para empezar, importa no perder de vista que la teoría benjaminiana de la traducción es polifacética, y que muchas de sus caras no comparecerán en estas páginas; por citar solo dos, muy relevantes: la criptoteología judaica que permea y nutre a la teoría, así como la filosofía de la reine Sprache (o lenguaje puro), cuya exposición parcial recae en la traductología. Con todo, antes de sumergirnos en "La tarea del traductor" es indispensable hacer una caracterización preliminar de la rica noción benjaminiana de lenguaje, tal como la expone en el ensayo "Sobre el lenguaje en general y sobre el lenguaje de los humanos" (1916). ${ }^{7}$

En este texto Benjamin define el lenguaje como "un principio dedicado a la comunicación de contenidos espirituales relativos a los objetos respectivamente tratados" $"$ y lo concibe al modo de un medium comunicativo para todas las realidades, no solamente la humana: "la comunicación por medio de la palabra es solo un caso particular del lenguaje humano [...] Pero el ser del lenguaje no solo se extiende sobre todos los ámbitos de la expresión espiritual del hombre [...] sino que se extiende sobre todo". ${ }^{9}$ Ahora bien, este panlingüismo implica una estratificación: "las diferencias entre lenguajes son diferencias entre medios distintos en densidad, y por lo tanto, distintos en graduación". ${ }^{10}$

Según la densidad comunicativa del medium lingüístico, Benjamin piensa en por lo menos tres formas o niveles de lenguaje:

i) El nivel del ser creador, divino y omnisciente. En este sentido, su lenguaje es un nombramiento creador, es decir, un lenguaje de nombres,

${ }^{7}$ Como señala Tackels: "Cuando redacta en Múnich 'Sobre el lenguaje en general y sobre el lenguaje humano en particular', Benjamin tiene 24 años. Originalmente el texto no estaba destinado a ser publicado; debía sencillamente servir de apoyo escrito en las discusiones teológicas profundas entabladas con Scholem en los meses precedentes" (Bruno Tackels, op. cit., p. 79).

${ }^{8}$ Walter Benjamin, "Sobre el lenguaje en general y sobre el lenguaje de los humanos", en Para una crítica de la violencia y otros ensayos. Iluminaciones IV, 1991, Madrid, Taurus, trad. de Roberto Blatt, p. 59.

${ }^{9}$ Loc. cit.

${ }^{10}$ Ibid., p. 64. 
inmediatamente creador de las cosas nombradas por esos Nombres. La lógica del verbo divino es simple: al pronunciar el Nombre, Dios crea la cosa inmediatamente y la conoce integralmente al mismo tiempo. En el verbo divino, crear el ser, nombrar el ser y conocer el ser son una y la misma cosa.

ii) El nivel de la naturaleza y su lenguaje mudo. [...] Con este proceso de nombramiento-creación, las cosas advienen al ser como lenguaje, ya que realmente se trata, en el silencio de las cosas, de un lenguaje. Los seres mudos de las cosas proceden del lenguaje, salen directamente del lenguaje divino que les da el ser. Los nombres de las cosas no son otra cosa — según Benjamin - que los nombres pronunciados por Dios, pero vaciados, al final de esa pronunciación, de su sonoridad divina, de su poder creador. Así pues, las cosas conservan en silencio la marca silenciosa del nombre que las creó.

iii) El nivel de la realidad humana [...] Dios transmite a Adán el fabuloso poder de escuchar en el mutismo de la naturaleza el eco del nombre divino que preside su creación. Al escuchar la naturaleza, Adán recibe de Yahvé el poder de (re)nombrar las cosas, de proferir su nombre, el nombre por medio del cual Dios las creó. ${ }^{11}$

De acuerdo con la articulación de estos tres niveles, existe en la instancia del lenguaje adánico una posibilidad de reactivación o redención sonora del nombre divino silenciado y encapsulado en las criaturas no humanas después del acto performativo absoluto de su proferimiento/ creación por parte de Dios; al menos esta posibilidad se declara en el campo de lo paradisíaco. Pero en el contexto de la expulsión del Edén y la caída de Adán y Eva (cuyas consecuencias lingüísticas se hacen manifiestas en el relato de la torre de Babel) el lenguaje humano se degrada. Así las cosas, en el estrato del lenguaje humano se distingue el lenguaje adánico — que comunica la esencia de las criaturas — del lenguaje de

${ }^{11}$ Tackels, op. cit., pp. 535-536. A propósito de la importante diferencia entre lenguaje divino y lenguaje adánico: "Mientras que, en el lenguaje divino, el potencial creador y el cognitivo alcanzan una identidad absoluta, el lenguaje humano permanece deficitario en comparación con esta unidad de 'palabra' y 'nombre'. De acuerdo con su esencia no es creador sino cognitivo" (Uwe Steiner, "Crítica” (trad. de Mariela Ferrari), en Michael Opitz y Erdmut Wizila (eds.), Conceptos de Walter Benjamin, 2014, Buenos Aires, Las cuarenta, p. 251). 
signos convencionales, multiplicado en las lenguas posbabélicas, ${ }^{12}$ incapaz de otra tarea que la de señalar extrínsecamente las cosas:

El pecado original es la hora de nacimiento de la palabra humana, en cuyo seno el nombre ya no habita indemne. Del lenguaje de nombres, el conocedor, podemos decir que su propia magia inmanente salió de él para ser, expresamente, mágica desde afuera. Se espera que la palabra comunique algo (fuera de sí misma). Este es el verdadero pecado original del espíritu lingüístico. La palabra como comunicante exterior; esto es simultáneamente una parodia de lo expresamente inmediato y además la decadencia del espíritu lingüístico bienaventurado, el adánico, que se yergue entre ambos. ${ }^{13}$

En consideración de esta jerarquía onto-lingüística, en el ensayo de 1916 Benjamin apunta, a propósito de la traducción:

Es preciso fundamentar el concepto de traducción en el estrato más profundo de la teoría del lenguaje, porque es de demasiado e imponente alcance como para ser tratado a posteriori $[. .$.$] Alcanza su plena signifi-$ cación con la comprensión de que cada lenguaje superior, con la excepción de la palabra de Dios, puede ser concebido como traducción de los demás. La traductibilidad de los lenguajes está asegurada por el enfoque antes mencionado según el cual los lenguajes están relacionados por ser medios de diferenciada densidad. La traducción es la transferencia de un lenguaje a otro a través de una continuidad de transformaciones. La traducción entraña una continuidad transformativa y no la comparación de igualdades abstractas o ámbitos de semejanza. ${ }^{14}$

A partir de estos elementos podemos acotar la noción de traducción que estudiaremos en el ensayo "La tarea del traductor". Se trata en este caso de la traducción, no en su sentido omniabarcante, sino en el bien

${ }^{12}$ Sobre las implicaciones comunicativas, pragmáticas y traductológicas del mito de Babel en el pensamiento de Benjamin, véase Jacques Derrida, "Des Tours de Babel”, en Psyche I, 1987, París, Galilée, pp. 203-236.

${ }^{13}$ Walter Benjamin, "Sobre el lenguaje en general y sobre el lenguaje de los humanos", pp. 70-71.

${ }^{14}$ Ibid., p. 69. 
específico de la traducción interlingüística, es decir, la que, en términos de Benjamin, se practica de un lenguaje semiótico (verbal) a otro, ambos situados en el mundo humano posbabélico, ambos constituidos y afectados por la exterioridad y la intencionalidad de palabras que apuntan como signos hacia las cosas, o bien — en el acompasamiento de la lengua fuente con la lengua meta - hacia otras palabras en otro idioma.

3. Para continuar, resulta imperativo esclarecer algunos supuestos fenomenológicos sobre la naturaleza del lenguaje que gobiernan el modelo traductológico benjaminiano tal como se expone en Die Aufgabe des Übersetzers. En la consideración de los componentes verbales y discursivos de una lengua, pero sobre todo en lo tocante al léxico, Benjamin distingue entre la intención lingüística (Intention) y el modo de significar(Art des Meinens). Según esto, dos sinónimos interlingüísticos como la palabra alemana Brot y la palabra francesa pain (equivalentes al castellano 'pan') comparten la intención y difieren en el modo de significar. Como sería engañoso analogar esta distinción a la existente entre los conceptos de denotación y connotación, conviene intentar reformularla según la pauta de la fenomenología husserliana.

De acuerdo con esta fenomenología la forma de todo acto de pensamiento - incluidos los que se hacen en el dominio del lenguaje - es la intencionalidad, es decir, el esfuerzo de atención dirigida que la conciencia despliega hacia su objeto: "Entendemos por intencionalidad la peculiaridad de las vivencias de 'ser conciencia de algo [...] En todo cogito actual, una 'mirada' que irradia del yo puro se dirige al 'objeto' que es el respectivo correlato de la conciencia, a la cosa, la relación objetiva, etc., y lleva a cabo la muy diversa conciencia de él". ${ }^{15}$ Según esta tópica de la conciencia, cada acto intencional emana de un polo pensante, o noético, y alcanza su destino en un polo pensado, o noemático, lo cual implica que el proceso pensante, o noesis, comprende una estructura dual, así como una distancia y una correlación entre los dos polos.

${ }^{15}$ Edmund Husserl, Ideas relativas a una fenomenología pura y una filosofía fenomenológica, 1992, México, Fondo de Cultura Económica, trad. de José Gaos, p. 198. 
A propósito de esa distancia constitutiva, cabe insistir en que, por su causa, toda intelección es intelección de algo trascendente al yo que intelige y hacia lo cual dirige un rayo de atención para captarlo; la conciencia no ejecuta sus operaciones representativas en la inmanencia del polo intencional, sino que tiene que volcarse a la exterioridad del polo intencionado para apoderarse ahí de su objeto. Como veremos, este apuntar hacia fuera y salir de sí la conciencia hacia su objeto es el componente de la intencionalidad husserliana del que Benjamin obtiene más provecho heurístico en su teoría de la traducción.

Ahora bien, tanto si en el polo intencionado se capta un contenido de naturaleza eidética (por ejemplo: una figura geométrica), como si el contenido es de índole perceptiva (es decir, un escorzo de la realidad empírica), es preciso distinguir entre la captación intencional en puridad y sus modalidades. La diferencia entre, digamos, un gato percibido y el mismo gato recordado o imaginado o inclusive soñado no es de orden eidético: el gato intencionado es fenomenológicamente el mismo en esos distintos actos; los que divergen son los actos noéticos que captan al gato, y divergen de acuerdo con las modificaciones de conciencia a través de las cuales se intenciona un solo y mismo eidos gatuno (en el modo del ver, en el del evocar, en el del libre fantasear, en el del soñar). ${ }^{16}$ Hasta aquí Husserl.

4. Si ahora extrapolamos la noción de intencionalidad al universo temático de "La tarea del traductor", notaremos una analogía entre ella y la 'intención lingüística' de Benjamin, y otra entre la 'modalidad intencional' del primer filósofo y el 'modo de significar' del segundo. "En las palabras Brot y pain lo intencionado es lo mismo, pero el modo de significar no lo es", ${ }^{17}$ dice Benjamin. En otros términos: si, abusando de la prosopopeya, nos figuramos a estas dos palabras como focos de intencionalidad, entonces, desde un punto de vista referencial, ambas apuntan hacia el mismo correlato eidético: ese alimento que en español llamamos

${ }^{16}$ A propósito de las modalidades intencionales y la invariancia eidética, véase Edmund Husserl, Ideas relativas a una fenomenología pura y a una filosofía fenomenológica, § 99 "El núcleo noemático y sus caracteres en la esfera de las percepciones y las representaciones", pp. 243-245.

${ }^{17}$ Die Aufgabe des Übersetzers, p. 14. 
'pan', ${ }^{18}$ en tanto que desde un punto de vista semántico, cada cual se apodera de ese correlato según una modalidad idiomática propia.

Ahora bien, ¿en qué consiste esta modalidad? El autor se limita a decir que "es por el modo de significar que estas palabras son distintas para un alemán y para un francés". ${ }^{19}$ Nada nos impide suponer que el 'modo de significar' de una palabra (o, al menos, de una palabra categoremática) está conformado por un haz de rasgos que, por motivos que explicaré un poco más adelante, nos conviene imaginar como un revestimiento del núcleo eidético del vocablo mismo. Este haz incluye las características fónicas y morfológicas de la palabra, su comprensión y extensión semánticas, sus posibilidades combinatorias en el nivel sintáctico, así como el espectro de sus valores pragmático-discursivos. Enfocado el asunto de este modo, puede resultar más claro por qué, insertas en sus respectivos sistemas de lengua y contextos culturales, las palabras Brot y pain "no son intercambiables" e inclusive "se esfuerzan por excluirse", ${ }^{20}$ es decir, sus respectivos dominios modales no son conmensurables.

De hacer en este punto de la exposición el intento de reconstruir en una figura coherente los postulados de Benjamin que he mencionado, el resultado que obtendríamos sería descorazonador. Me explico: si el aspecto netamente comunicativo de una lengua reside en el ámbito de lo ideal puro, y si además el modo de significar de esta es tan idiomático que resulta incompatible con el de otra, entonces el único recurso del traductor literario es desprender el contenido eidético del texto fuente de su revestimiento modal aborigen para envolverlo en una piel modal distinta y, en el mejor de los casos, equivalente a la previa: la de la lengua meta. Pero ello es estéril, pues en el caso de la obra literaria lo comunicativo es inesencial y lo decisivo está configurado según el modo de significar. Comienza uno aquí a sentir el peso de la célebre afirmación benjaminiana: "no hay musa de la traducción". ${ }^{21}$

${ }^{18}$ Ahora bien, que para realizar esa indicación referencial cada una de esas palabras deba constituir el objeto empírico 'pan' en el polo intencionado de un acto de significación denotativa, es decir, en el componente semántico de su propio código, es asunto ajeno a las reflexiones de Benjamin.
${ }^{19}$ Loc. cit.
${ }^{20}$ Loc. cit.
${ }^{21}$ Ibid., p. 16. 
5. Con todo, hay otro camino para traducir sin confinarse en la esterilidad de la recodificación de un contenido inesencial y sin quedar varado en la inconmensurabilidad de dos modos excluyentes de significar. Pero para entrar en él es preciso repensar el proceso traductológico en los términos más isomorfos que se pueda con la arquitectónica de la intencionalidad fenomenológica. Recordemos entonces: en todo acto intencional la conciencia representativa está separada de su contenido, no fusionada con él; la distancia entre el polo intencional y el polo intencionado es la clave del asunto; para que el intelecto capte su objeto tiene que llegar a él desde lejos y desde fuera. En este orden de cosas, Benjamin tematiza la distancia fenomenológica en por lo menos tres pasajes de "La tarea del traductor".

Así, a propósito de la manera en que el poeta y el traductor se relacionan con los contenidos eidéticos lingüísticos, nuestro filósofo apunta: "la intención del poeta es inmediata, primera, intuitiva; la del traductor, derivada, última, conceptuosa." ${ }^{22}$ Dicho de forma menos hermética, la intencionalidad del texto traducido está más lejos del contenido noemático primario que la del texto fuente, pues para llegar a él tiene que pasar por el tamiz del modo de significar de este, atravesando esa membrana modal. Cabe, sin embargo, preguntarse si el texto traducido logra cruzar la barrera semántica del original o si esta es impermeable, es decir, si está constituida no tanto como membrana, sino más bien a la manera de una coraza esmaltada que solo se deja intencionar a sí misma, ofreciéndosele como objeto primario al texto de la traducción, cuyos esfuerzos por traspasarla, que la coraza repele, no logran acceder al núcleo noemático del texto original.

Esta parece ser la certeza de Benjamin, tal como se desprende del segundo de los pasajes del texto, en donde se hace rendir heurísticamente al concepto de distancia fenomenológica: "La relación entre contenido y lenguaje es muy diferente en el original y en la traducción. Estos forman ciertamente una unidad en el original, como la de una fruta y su piel, en tanto que el lenguaje de la traducción envuelve su

${ }^{22}$ Loc. cit. 
contenido como un manto real de amplios pliegues". ${ }^{23}$ Supongamos una fruta, una ciruela, no demasiado madura, de pulpa firme y con la piel perfectamente ceñida a la carne: he aquí una imagen de la adecuación exacta entre el contenido noemático del texto original (la pulpa) y el modo de significar de la lengua en que está codificado (el tegumento). Ahora representémonos el modo de significar del texto traducido como un tejido menos flexible y, sobre todo, no adherido por naturaleza a ningún objeto al que, aun así, cubriera... ¿Cuál sería su contenido? No queda más que responder: el texto fuente. Así las cosas, la fruta del texto original envuelta en el manto de la traducción tendría un aspecto distinto recubierta por él que desnuda, y, puestos a juzgar si bajo el manto se oculta una ciruela, el juicio solo podría ser hipotético.

Además, no perdamos de vista la imposibilidad de acercar todavía más la tela de la traducción a la pulpa del original: el intento de recubrirla directamente con el manto sería un despropósito: habría que desollar la ciruela primero, y luego adherirle — prótesis fallida — una absurda piel de tela. Ante estas dificultades, el texto traducido tiene que resignarse a quedar separado del contenido del texto original por la película impermeable del modo de significar del original mismo; en otras palabras, el texto meta nunca puede llegar a la pulpa noemática del texto fuente, ni por su designio ni según una intuición empática (una vez más: "no hay musa de la traducción"), sino que debe esforzarse en ceñir los accidentes semánticos del original con su propio modo de significación, pues esos accidentes semánticos son el único objeto al alcance de su intencionalidad. Abocada a cumplir este propósito, la traducción (ese texto que envuelve otro texto) ha de procurar satisfacer lo mejor posible dos exigencias: la primera, no perder contacto con la superficie lingüística del original; la segunda, no romperse en el esfuerzo de mantener ese contacto. En el orden de la técnica traductológica, Benjamin postula algo casi imposible de lograr: traducir calcando al máximo y trasponiendo al mínimo.

En un tercer pasaje del texto, la arquitectónica de la distancia fenomenológica se presenta en los términos de un complejo metafórico

${ }^{23}$ Ibid., p. 15. 
distinto: "La traducción no se encuentra, como la obra poética, dentro del bosque del lenguaje, sino que desde fuera, frente a él, y sin meterse en él, dirige sus llamados al original hacia los lugares en los que el eco puede repetir, en el idioma de la traducción, la resonancia de la obra en el idioma extranjero". ${ }^{24}$ Como en el símil de la fruta, hay aquí una lejanía que no se deja abreviar y que impide que el traductor se adentre en el bosque de la lengua fuente, donde se escabulle el texto original; como en los cuentos maravillosos, si el cazador se interna en ese bosque corre el riesgo de perderse y no salir; en cambio, la renuncia a apoderarse de la pieza por propia mano se compensa con la posibilidad de atraparla desde lejos, con una trampa sonora: buscando el ángulo adecuado para lanzar enunciados en la lengua meta y estimar la fidelidad de su respuesta en la lengua origen, la traducción puede lograrse como eco del original. ¿Y acaso el eco no puede analogarse a un envoltorio, a una capa de sonido que deja escuchar la forma que reviste? Si Benjamin hubiera conocido los aparatos de ultrasonido, quizá los habría juzgado máquinas traductoras: traductores ecográficos. Por cierto, notemos que en este caso la película sonora corre los mismos riesgos que su análogo textil en la metáfora de la fruta: distorsionarse por holgura o reventar en el silencio por un excesivo esmero de precisión.

Llegados aquí, es admisible transcribir las palabras con que Benjamin formula la tarea del traductor: "Consiste en encontrar, en el idioma al que se traduce, aquella intención lingüística que pueda despertar en este el eco del original". ${ }^{25}$ Digámoslo una vez más: no se trata de encontrar el eco que arroje en la lengua meta el contenido eidético del original (pues este solo es accesible desde el original), sino el eco producido por la refracción de la intencionalidad lingüística del texto meta en la superficie del texto fuente.

6. Ahora bien, una vez comprendido el pensamiento traductológico de Benjamin en su sentido, digamos, artesanal, cabe preguntarse si la traducción así concebida alcanza el estatuto de actividad hermenéutica solamente en este plano operativo. En efecto, buscar en la lengua

${ }^{24}$ Ibid., p. 16.

${ }^{25}$ Loc. cit. 
meta un eco del original implica realizar conjeturas lingüísticas complejas a favor de la comparación de dos universos idiomáticos inconmensurables, conjeturas que no pueden aspirar al estatuto de casos de una regla, ni siquiera al de máximas procedimentales, en la medida en que la sobreabundancia de elementos heterogéneos que el traductor tiene que ajustar mientras realiza su trabajo ecográfico rebasa las posibilidades de generalización de cualquier fórmula. No se me malinterprete: no pierdo de vista que el ámbito conjetural en el que se mueve el traductor tiene unos límites normativos: los de las leyes sistémicas de las lenguas con las que trabaja; solamente busco destacar que el ejercicio de jurisprudencia que el traductor tiene que sacar adelante para cumplir con la tarea benjaminiana es, por así decirlo, infinitesimal. Dicho en otros términos: a partir de un corpus de traducciones ecográficas "exitosas", por amplio que fuere, no podría construirse una normativa traductológica, sino que habría que conformarse con estudiarlo en términos casuísticos.

Solo esto bastaría para no despreciar el aspecto artesanal de la traducción, y el propio autor así lo estima. Un pasaje del ensayo, que ya cité incompleto dos veces, reza: "No hay musa de la filosofía, tampoco hay musa de la traducción. Prosaicas, ${ }^{26}$ empero, como los artistas sentimentales desearían que fueran, ni una ni otra lo son". ${ }^{27}$

No obstante lo dicho, sabemos que el alcance del término hermenéutica es más amplio. Cuando menos desde Verdad y método (1960), gracias a la reconstrucción histórica que hace Gadamer del Ars interpretandi, estamos al tanto de que la hermenéutica no es solo una tejné, ni nada más el paradigma metodológico de comprensión de las ciencias idiográficas (las Geisteswissenschaften de Wilhelm Dilthey), sino sobre todo una forma humana de ser en el mundo y, por extensión, una disposición cognitiva y un modo simbiótico de relación con las entidades culturales. Es en este orden de significación de la palabra hermenéutica que vale la pena emprender un segundo recorrido por el texto de

${ }^{26}$ Benjamin usa el adjetivo banausisch, que etimológicamente significa 'artesanal', pero en sentido corriente es término peyorativo: 'inculto', 'agreste', 'pedestre'.

${ }^{27}$ Ibid., pp. 16-17. 
Benjamin con el afán de valorar el rendimiento gnoseológico de la traducción literaria.

En uno de los escasos pasajes del ensayo que proveen definiciones positivas, el autor apunta: "La traducción es una forma (Form). Para captarla como tal, hay que volver al original, pues en él yace su ley, la cual decide su traducibilidad (Übersetzbarkeit)". ${ }^{28}$ Comprendemos ya que la traducción es literalmente una forma lingüística que reviste a otra; lo interesante ahora es explorar el concepto de traducibilidad. Benjamin encuentra en él dos sentidos:

La pregunta por la traducibilidad de una obra es doble. Puede significar: ¿encontrará la obra en la totalidad de sus lectores alguna vez un traductor? O bien, y más propiamente, ¿admite traducción la esencia de la obra y, por lo tanto, según su modo de significar, anhela esa traducción? En principio, la primera pregunta solo admite una respuesta problemática; la segunda, una respuesta apodíctica. ${ }^{29}$

Para el autor, "solamente una mentalidad superficial" consideraría ambas preguntas de igual peso, o bien, negaría la independencia de la segunda respecto de la primera. En efecto, solo en el terreno contingente de los hechos puede saberse si una obra literaria ha logrado ser traducida. Cosa muy distinta es afirmar que "la traducibilidad de las creaciones lingüísticas debe tomarse en cuenta incluso si ellas fueran intraducibles para los humanos [...] La traducibilidad es una propiedad esencial de ciertas obras, lo cual no significa que sea esencial que se las traduzca, sino que una significación específica radicada en el original se manifiesta en su traducibilidad". ${ }^{30}$

A manera de glosa a los pasajes citados: cada obra literaria es única, un individuo verbal, un singular, y no un caso discursivo particular subsumible sin más en un repertorio de universales lingüísticos. Por eso la traducibilidad del texto literario es facultad propia de cada obra, y por eso también la cuestión de si una obra es traducible tiene que ver

${ }^{28}$ Ibid., p. 9.

${ }^{29}$ Loc. cit.

${ }^{30}$ Loc. cit. 
en lo esencial con su modo de significar y no con el hecho contingente de si un traductor empírico es capaz de acercarse desde otra lengua a ese modo de significación.

Pero lo decisivo, a mi entender, es que Benjamin postula (al menos en el caso de ciertas obras, aunque no especifique cuáles) la existencia de significaciones inherentes a los textos literarios que permanecen embrionarias en ellos mientras no son trasladadas a otra esfera lingüística. En esta idea se aloja en su sentido más noble el rendimiento hermenéutico de la traducción. Me explico: la obra literaria, inmersa en su medio lingüístico aborigen, no expresa exhaustivamente su potencial semántico; tan solo puede hacerlo si se expande en otro medio lingüístico, el de su traducción. Recordemos por un momento la arquitectónica de la distancia entre texto fuente y texto meta que revisamos más arriba: en aquel momento la orientación axiológica de la distancia conducía de la traducción al original, según un movimiento, digamos, centrípeto de adecuación entre un texto derivado y más lejano del núcleo eidético (la traducción) y un refractario texto original que acaparaba el eidos para sí y le daba la espalda al manto que lo cubría. En este momento es necesario que cambiemos la orientación axiológica de la distancia entre original y traducción a favor de la segunda: ya se la vea como un vestido, ya como un eco del original, lo notable ahora es que la traducción expresa rasgos de significación del original que no podían manifestarse desde la desnudez, o bien, desde el emboscamiento de este. Así pues, la traducción también consigue enriquecer el universo semántico del texto fuente.

A este respecto, debo admitir que Benjamin es menos entusiasta que yo, al menos estilísticamente. El autor concibe el vínculo entre el original y la traducción como "vital" (ein Zusammenhang des Lebens), ${ }^{31}$ pero formula esa vitalidad de esta manera: "[la traducción] mantiene por la fuerza de la traducibilidad un vínculo de cercanía con el original; este vínculo es tan íntimo justamente porque para el original carece de importancia [...] Así como las manifestaciones de vitalidad están íntimamente vinculadas a los seres vivos sin tener importancia para

${ }^{31}$ Ibid., p. 10. 
ellos, así la traducción emana del original, no tanto de su vida como de su 'supervivencia' (Überleben)". ${ }^{32}$ El último pasaje es críptico, sobre todo por la ambigüedad del término Überleben, que en este contexto no debe entenderse como si Benjamin sugiriera que el original necesita las traducciones para mantenerse vigente en el ámbito histórico de la recepción, ${ }^{33}$ sino más bien como si esa "sobre-vida" o inclusive "ultravida" del original señalara un excedente, una irradiación, superflua para su fuente, tan irrelevante para ella como resultan espontáneas y, por así decir, suntuarias para la conservación de un ser viviente sus meras manifestaciones de vitalidad. Esta lectura del pasaje la confirma otro: "[las traducciones] no están al servicio de la obra — como pretenden los malos traductores para justificar su trabajo_-, sino que a ella deben agradecer su existencia. En las traducciones alcanza la vida del original su siempre renovado, más amplio y último despliegue". ${ }^{34}$

En suma, me parece que una posición crítica ecuánime a propósito del vínculo que según Benjamin une al original con la traducción sería la siguiente: aunque para la 'vida' lingüística del original es indiferente llevar a eclosión en otra lengua las esporas de sentido que no lograron estallar en el idioma aborigen, es decir, aunque para la 'fisiología' semántica del original la traducibilidad embrionaria es un apéndice supernumerario, ello no niega que el esfuerzo hermenéutico de gestar el sentido de ese embrión amplía el ámbito de significación de la obra, de modo que ella logra desplegar una atmósfera semántica nueva, a la que no se puede acceder desde el monolingüismo del original.

7. Evaluemos una última vez, y por la vía del excurso, el rendimiento hermenéutico de esta facultad expansiva de la traducción. En su tesis doctoral, presentada en la Universidad de Berna en 1918 y editada dos años después con el título de El concepto de crítica de arte en el romanticismo alemán, Benjamin dedica largos tramos de la argumenta-

${ }^{32}$ Loc. cit.

${ }^{33}$ Independientemente de que las traducciones puedan fungir como índices en la escala de la recepción epocal de la obra. Dice al respecto Benjamin: "Las traducciones que hacen algo más que comunicar, surgen cuando una obra ha alcanzado la época de su fama" (ibid., p.11).

${ }^{34}$ Loc. cit. 
ción a exponer el alcance epistemológico de la filosofía romántica de la reflexión. Este no es el lugar adecuado para entrar en detalles acerca del modo en que el autor explica cómo el concepto de reflexión de Fichte estimuló el surgimiento del paradigma de la crítica literaria de Friedrich Schlegel, así como desencadenó el llamado 'idealismo mágico' del poeta Novalis; aun así, nos conviene retener de la exposición benjaminiana dos o tres postulados básicos de esa filosofía.

Primero, que la reflexión o autoconciencia representa para la mera conciencia un incremento de saber: en efecto, saber que se sabe, el saber mediado en su reflejo, es cualitativamente superior al saber de primer grado de la conciencia inmediata, pues el que meramente sabe, no sabe que sabe. Segundo, que la autoconciencia puede iterarse en sucesivos niveles de reflexión indefinidamente, de lo cual se sigue que el proceso del saber es progresivo (pues avanza de nivel reflexivo en nivel reflexivo) e interminable (pues la reflexión tiene la estructura de una construcción en abismo). Tercero, que la autoconciencia no es privativa del sujeto pensante, sino que también participa de ella el objeto con el que el sujeto establece la relación epistémica. Este último punto es decisivo: "No solamente los hombres pueden ampliar su conocimiento a través de los grados superiores del autoconocimiento en la reflexión, sino también, y en la misma medida, los objetos naturales", ${ }^{35}$ escribe Benjamin; a lo que añade: "Observar una cosa significa empujarla hacia el autoconocimiento. Que el experimento alcance el éxito depende de en qué medida el experimentador esté en condiciones de aproximarse al objeto y de incluirlo en sí", 36 e inclusive agrega: "En la base de este experimento no yace ninguna interrogación a la naturaleza. Antes bien, la observación considera el autoconocimiento germinal en el objeto, o más bien ella misma, la observación, constituye ese autoconocimiento germinal del objeto". ${ }^{37}$

En el paradigma epistemológico del romanticismo alemán, no solo los seres naturales no humanos son susceptibles de autoconciencia: de

${ }^{35}$ El concepto de crítica de arte en el romanticismo alemán, 1995, Barcelona, Península, trad. de J. F. Yvars y Vicente Jarque, p. 89.

${ }^{36}$ Ibid., p. 92.

${ }^{37}$ Ibid., p. 93. 
manera análoga al naturalista "experimentador", que logra conocer una criatura cuando irrita en ella el germen de la reflexión, así el crítico literario cumple con su tarea, no al evaluar con patrones extrínsecos a la obra su rendimiento estético, sino más bien cuando consigue aguijonear en ella su "criticabilidad", es decir, al permitir que el sentido de la misma acceda a un nivel de reflexión superior en el discurso crítico que él elabora: "La crítica es algo semejante a un experimento en la obra de arte, en virtud del cual se estimula la reflexión por la que la obra es elevada a la conciencia y al conocimiento de sí misma". ${ }^{38}$ En este caso: "El sujeto de la reflexión es, en el fondo, el producto artístico mismo, y el experimento no consiste en la reflexión sobre un producto, que no podría esencialmente transformarlo [...] sino en el despliegue de la reflexión — esto es, del espíritu-en el producto". ${ }^{39}$

Hasta aquí la digresión. Como puede verse, en el pensamiento del primer romanticismo alemán, la crítica literaria, de modo análogo al paradigma benjaminiano de la traducción, cumple el papel hermenéutico de expandir el sentido del texto que critica: un sentido endógeno, seminal, que el crítico literario ayuda a manifestar, así como el traductor idóneo es el agente de germinación de una semilla lingüística trasterrada a otra lengua; en ambos casos, el crítico y el traductor cumplen con su encomienda "solo cuando estos no son intelectos empíricos, sino niveles de reflexión [de la obra] personificados" ${ }^{40}$ En concordancia con esto, criticabilidad y traducibilidad son en el pensamiento benjaminiano términos homólogos, e incluso es plausible pensar que la traducibilidad de la que se ocupa el ensayo de 1923 es un caso concreto de apropiación por parte de Benjamin de la más amplia idea de criticabilidad que encontró en los románticos que protagonizan la tesis de 1918. Una confirmación de este último aserto lo encontramos en una glosa a una cita de Novalis, que se halla justo en este último libro:

En ejemplos de esta crítica positiva y plenificadora está pensando Novalis cuando, a propósito de cierta clase de traducciones a las que denomina

${ }^{38}$ Ibid., p. 101.

${ }^{39}$ Loc. cit.

${ }^{40}$ Ibid., p. 104. 
míticas dice: "Estas representan el carácter acabado y puro de la obra de arte individual. No nos dan la obra de arte real, sino el ideal de la misma [...]". En la medida en que aproxima recíprocamente crítica y traducción, tal vez Novalis piensa en una permanente transposición mediática de la obra desde un lenguaje al otro, una concepción que, partiendo de la naturaleza infinitamente enigmática de la traducción, resulta tan lícita como cualquier otra. ${ }^{41}$

A mi parecer, esas traducciones míticas que tienen la virtud de llevar a la obra literaria a su acabamiento, y en las que Novalis tal vez pensó como ideales, son un punto de partida del modelo traductológico que Benjamin propuso en "La tarea del traductor" algunos años después de su estudio sobre los románticos alemanes, modelo del que yo he querido ofrecer aquí un perfil, si bien incompleto, ojalá que nítido.

${ }^{41}$ Ibid., p. 107. 